\title{
Significados de violência familiar contra o idoso na perspectiva de profissionais da Atenção Primária à Saúde
}

\author{
Meanings of family violence against the elderly \\ from the standpoint of professionals in Primary Healthcare
}

Ana Claudia Nunes de Souza Wanderbroocke ${ }^{1}$

Carmen Leontina Ojeda Ocampo Moré ${ }^{2}$

${ }^{1}$ Programa de Pósgraduação em Psicologia, e não Núcleo de Pesquisa em Psicologia, Universidade Tuiuti do Paraná. Rua Sydnei A. Rangel Santos 238, Santo Inácio. 82010 330 Curitiba PR. anawdb@gmail.com ${ }^{2}$ Programa de Pósgraduação em Psicologia, Centro de Filosofia e Ciências Humanas, Universidade Federal de Santa Catarina.

\begin{abstract}
This qualitative study sought to analyze the meanings attributed to domestic violence against the elderly by professionals in Primary Healthcare. A total of 10 health professionals from different backgrounds from a renowned health unit for care of the elderly took part, and the data was collected through semi-structured interviews. Taking the Grounded Theory as a benchmark, the data were integrated and organized into categories, subcategories and elements of analysis. The results revealed the participants' expectation that the family acts as support and protection for the elderly and that domestic violence violates this principle. The significance of abuse of the elder was found to be grounded in the idea "of the frail and dependent elderly person," limiting the viewing of cases that do not fit this profile.
\end{abstract}

Key words The elderly, Health team, Domestic violence, Primary Healthcare
Resumo O presente estudo de cunho qualitativo buscou analisar os significados atribuídos à violência familiar contra o idoso, por profissionais que atuam na atenção primária à saúde. Participaram 10 profissionais com diferentes formações, de uma unidade de saúde de referencia para idosos, sendo os dados coletados por meio de entrevistas semiestruturadas e analisados segundo os princípios da Grounded Theory. Os dados foram integrados e organizados em categorias, subcategorias e elementos de análise. Os resultados evidenciaram que os participantes demonstraram a expectativa de que a família funcione como amparo e proteção e que a violência familiar é o que fere esse princípio. O significado de violência familiar contra o idoso mostrou-se alicerçado na ideia "do idoso frágil e dependente", limitando a visualização de casos que não se enquadram nesse perfil. Palavras-chave Idoso, Equipe de saúde, Violência familiar, Atenção primária 


\section{Introdução}

A discussão sobre violência como assunto relacionado à saúde tem inicio na segunda metade do século XX pela denúncia de profissionais da área em relação aos abusos perpetrados contra crianças, adolescentes e mulheres. A violência contra os idosos foi a última a ser contemplada nas agendas da política e da saúde, na maioria dos países $^{1}$. Contudo, a preocupação com esta parcela da população vem aumentando em razão do crescente contingente de idosos no mundo.

No Brasil, o assunto ganhou visibilidade a partir da década de 1990 com a promulgação e regulamentação da Política Nacional do $\operatorname{Idoso}^{2}$ e, posteriormente, com a aprovação do Estatuto do Idoso $^{3}$ e o Plano de Ação de Enfrentamento da Violência contra a Pessoa Idosa ${ }^{4}$. Apesar dessas Políticas Públicas que contemplam o problema da violência contra os idosos, a trajetória de implementação das mesmas está apenas no princípio ${ }^{5}$.

Um dos aspectos que dificulta colocar em prática as ações de saúde em relação à violência contra os idosos é que a maior parte ocorre nas famílias. Os dados de pesquisa ${ }^{6,7}$ revelam pontos de convergência a este respeito e indicam que: a) os principais agressores são os filhos homens, noras, genros e cônjuges; b) há uma forte associação com o uso de álcool e drogas; c) relação de dependência financeira entre pais e filhos; d) história de violência na família, e, e) sofrimento mental e psiquiátrico, entre outros. Devido aos vínculos de afeto e dependência entre o idoso e o agressor familiar, aumenta a dificuldade em revelar os abusos sofridos, em função do medo de retaliação ou vergonha do ocorrido, fazendo com que grande parte dos maus-tratos permaneça silenciada.

Como forma de promover saúde à população e detectar precocemente situações potencialmente prejudiciais ao bem-estar biopsicossocial, como as que envolvem violência familiar contra o idoso, os profissionais de saúde, principalmente os da atenção primária, têm atuação fundamental. Essa modalidade de assistência permite $\mathrm{o}$ acesso, proximidade e continuidade da atenção à população e entre outros benefícios, pode fortalecer a rede de suporte social para as pessoas em situação de vulnerabilidade, especialmente, os idosos que geralmente utilizam esses serviços com maior regularidade.

Apesar das orientações já disponíveis nos documentos que compõem as Políticas Públicas para o enfrentamento da violência familiar, o tema, por necessitar de compreensão e aborda- gem integralizada não é de fácil manejo para os profissionais da saúde, que ainda recebem pouco ou nenhum preparo para lidar com a questão ${ }^{8-10}$. Por outro lado, a produção de conhecimento nas áreas humanas e da saúde ainda é incipiente quando se trata de indicar medidas que guiem os profissionais na identificação e no manejo dos casos de violência contra o idoso.

Uma das questões que se coloca nesse sentido é a construção de significados acerca do que constitui violência familiar contra idosos e a identificação de quais destes encontram-se em situação de vulnerabilidade, uma vez que os significados acerca dos fenômenos guiam as condutas profissionais, ampliando ou restringindo as possibilidades de ação em relação aos problemas. Deve-se considerar, como uma particularidade nesse processo, o fato de que a violência não existe enquanto fenômeno objetivo, mas a sociedade a constrói através dos significados atribuídos aos fatos, eventos, ações, relacionamentos e valores que são reconhecidos como problema em determinadas circunstâncias e momento histórico específico, ou seja, os significados construídos em torno das violências são dinâmicos e mutáveis ${ }^{1,11,12}$.

Segundo a perspectiva adotada na presente pesquisa, os significados são estabelecidos com base em construções realizadas em um espaço intersubjetivo, pois a construção de um campo de significado decorre da inter-relação humana na linguagem. Dessa maneira, a realidade é definida pelos acordos narrativos coorganizados em conversações compartilhadas nos grupos sociais ${ }^{13,14}$.

Entende-se que a compreensão da atribuição de significados à violência contra o idoso gera, para os profissionais da saúde, a possibilidade de interferir nas fronteiras do sistema familiar uma vez enrijecidas pela presença de violência, podendo assim dar visibilidade às relações cotidianas sustentadoras de violências. Por sua vez, o entendimento dos significados no contexto da temática da violência, constitui-se numa necessidade de constante atualização, seja para sua identificação, para seu manejo, ou para evitar cair na naturalização do fenômeno.

Como base no apresentado, o presente artigo teve como objetivo compreender os significados atribuídos à violência familiar contra os idosos na perspectiva dos profissionais de saúde que atuam em uma UBS. Os dados apresentados fazem parte de uma pesquisa maior que buscou também os significados da violência familiar para idosos usuários da UBS e as redes sociais significativas para o enfrentamento da mesma. 


\section{Método}

\section{Participantes}

Participaram 10 profissionais da saúde que foram selecionados contemplando diferentes formações profissionais e pelo menos dois anos de trabalho na UBS onde a pesquisa foi realizada. Entre eles estavam 8 mulheres e 2 homens, com idade entre 24 e 68 anos. Três anos foi o menor tempo de exercício profissional entre os participantes e o maior, 42 anos. Quanto ao tempo de trabalho na US, variou entre 2 e 10 anos, sendo a média 5,8 anos. Os profissionais contemplados foram: médico, enfermeiro, técnico em enfermagem, assistente social, agente comunitário e odontólogo.

\section{Instrumento}

A coleta dos dados foi realizada por meio de entrevistas semiestruturadas, organizadas a partir de um roteiro para o levantamento de dados sociodemográficos e perguntas norteadoras relacionadas ao objetivo do trabalho contendo os seguintes tópicos: a) dados de identificação do profissional; b) experiência e formação para o trabalho com idosos; c) significado sobre violência familiar contra o idoso: conceito e tipos de violência familiar percebidas, fatores geradores, qualidade da relação entre idoso e familiar, perfil da vítima e do agressor e valores e crenças do entrevistado sobre o fenômeno.

\section{Procedimentos}

O primeiro contato com os participantes foi pessoal para agendar a data e o local para os encontros. Não houve recusa por parte de nenhum profissional. Durante toda a entrevista, priorizou-se uma relação dialógica e as perguntas foram introduzidas respeitando o fluxo narrativo dos participantes. Além das perguntas do roteiro, a entrevistadora pedia esclarecimentos ou maiores detalhes das falas em torno dos objetivos propostos.

Foi realizada uma entrevista com cada profissional e definiu-se o número de participantes em função da saturação de dados ${ }^{15}$, obtida a partir da sexta entrevista, quando se observou regularidades nas informações e reincidência temática referentes aos objetivos do presente estudo. Assim, delimitou-se em 10 entrevistas a fim de confirmar a recorrência dos dados obtidos.

O trabalho de campo teve início após a aprovação do projeto pelo Comitê de Ética em Pes- quisa da instituição educacional envolvida e da Secretaria Municipal de Saúde da cidade onde a pesquisa foi realizada. Todo o processo de pesquisa atendeu as normas da Resolução 196/96 do Conselho Nacional de Saúde, que correspondem às exigências referentes à ética nas pesquisas com seres humanos.

\section{Análise dos Dados}

Para a análise dos dados foi utilizado a Grounded Theory, proposto por Strauss e Corbin ${ }^{15}$. Esse método de análise permite trabalhar, comparar, integrar e categorizar os dados obtidos. A primeira etapa denominada codificação aberta, consiste em realizar sucessivas leituras das entrevistas, seguidas do processo de desmembramento, exame, comparações e categorização dos dados. $\mathrm{Na}$ segunda etapa, denominada codificação axial, realiza-se a construção das categorias principais, subcategorias e seus respectivos elementos de análise. Por último, o processo de codificação seletiva, permite integrar e refinar o conjunto de dados obtidos proporcionando uma compreensão integrada do fenômeno central.

A partir dos dados contidos nas narrativas dos profissionais foram estabelecidas sete categorias, cada uma delas com suas respectivas subcategorias e elementos de análise, possibilitando uma leitura transversal os dados, como também uma análise em profundidade do conteúdo emergente nas entrevistas. Todos os dados gravitaram em torno do fenômeno central da pesquisa, qual seja, os significados e os recursos de enfrentamento da violência familiar na perspectiva de profissionais da saúde. Duas categorias foram selecionadas para responder ao objetivo do presente artigo: a) Significados Atribuídos à Violência Familiar contra o Idoso e b) Aspectos Potencialmente Geradores de Violência Familiar contra o Idoso.

\section{Análise e discussão dos resultados}

A primeira categoria, Significados Atribuídos à Violência Familiar contra o Idoso, congregou subcategorias que abordaram a formação de imagens, ideias e pensamentos sobre o tema violência familiar contra o idoso pelos profissionais da saúde que atuam na UBS.

A subcategoria pela descrição de comportamentos de familiares em relação ao idoso descreveu a identificação na prática dos profissionais das diferentes manifestações de violência no modo de agir do familiar em relação ao idoso. Privar o 
idoso de recursos em proveito próprio foi comentado por profissionais que listaram diferentes formas pelas quais os familiares apropriam-se dos recursos financeiros ou do patrimônio da pessoa idosa, sendo o uso do cartão de aposentadoria o mais citado, mas também asilar o idoso para usufruir de seus recursos, tentativas de interdição e decidir sobre a utilização de seu patrimônio, como ilustrado na seguinte narrativa.

[...] Uma senhora herdou do marido um terreno muito grande e tinha uma casa nos fundos e a frente imensa. Com o dinheiro da aposentadoria fez uma casa de madeira super boa na frente. $O$ filho e a nora faliram, ela estava morando na casa da frente, a nova. Pois o filho veio e colocou ela nos fundos, trouxe as coisas dele e colocou na casa da frente e a idosa nos fundos. (P2)

$\mathrm{O}$ fato de a maioria dos profissionais citarem situações que caracterizam abuso financeiro vai ao encontro de pesquisa realizada em delegacias e órgãos de proteção ao idoso que indica ser essa a forma mais frequentemente denunciada nesses locais ${ }^{16}$. Dessa forma, pode-se pensar que a situação financeira do idoso se constitui um paradoxo, já que por um lado pode facilitar que ocupe um lugar de respeito, por outro aumenta sua vulnerabilidade a situações abusivas.

Foi feito referência a isolar o idoso ou priválo do convívio familiar e/ou social, seja em sua própria residência ou em instituições, dessa forma, o asilar também foi considerado pelos depoentes como maus tratos, conforme exemplos abaixo.

Vejo que é ter um idoso em casa e isolar ele, às vezes levar para um asilo e largar lá e a gente sabe de pessoas que não precisam estar lá. Então isso é violência, não é só chegar e bater no idoso, isso é agressão. (P8)

$\mathrm{O}$ conteúdo dessa narrativa remete à construção social acerca da velhice como uma fase de maior isolamento e de predomínio de declínio orgânico, bem como corrobora os dados pesquisas $^{17,18}$ que levantaram sua representação social, demonstrando que os profissionais da saúde tendem a associá-la à ideia de exclusão social e de dependência da família, como resultante da noção de declínio e, portanto, mais sujeitos à violência familiar.

Quanto à institucionalização dos idosos, esta ação foi considerada como forma de violência sempre que acompanhada de abandono por parte dos familiares, mas quando os familiares acompanham e monitoram a qualidade dos cuidados oferecidos foi vista como uma forma alternativa de oferecer cuidados ao idoso dependente face às inúmeras dificuldades que o cuidar envolve. Nesse sentido, pode-se notar que fazem referência ao idoso fragilizado e vitimizado, incapaz de agir por si e a família como a principal responsável pelos seus cuidados e bem-estar.

Na mesma linha de raciocínio, deixar de cuidar do idoso dependente foi indicado como violência pelos profissionais, que enfatizaram a importância dos cuidados com higiene pessoal, alimentação e prevenção de quedas, conforme o seguinte exemplo.

Tirar a autonomia do idoso foi citado por participantes que verificaram que algumas famílias privam a pessoa idosa de ter vida própria, seja porque os familiares se preocupam e acabam decidindo por eles como uma forma de proteção ou por considerarem que os idosos já não têm mais desejos ou direitos, como iniciar um novo relacionamento afetivo após a separação ou viuvez, e devem auxiliar os filhos e netos naquilo que precisam.

O seguinte exemplo ilustra a forma de pensar de uma profissional da UBS, que verificou entre as mulheres idosas que atende as mesmas questões que vivenciava com seus próprios familiares.

Eu vejo muito assim, eu acho violência uma mãe jovem dizer para sua mãe ficar cuidando dos filhos quando ela precisa, eu acho que é certo assim, eu quero ajudar a cuidar dos meus netos, pois bem, minha filha ou meu filho estabeleçam o dia que eu vou cuidar para eu organizar a minha vida. Eu falava ontem com uma senhora que dizia 'não posso me comprometer porque a minha filha ela nunca marca hora para me solicitar para eu ficar com os netos, de repente, não estou esperando e ela me solicita', eu acho isso uma violência. Isso é achar que o idoso já viveu, agora ele pode ficar disponível. ( $\mathrm{P} 6$ )

A situação acima ilustra que além das pressões externas e das mudanças na estrutura das famílias na atualidade, o vínculo existente entre o idoso e seus familiares também devem ser levados em conta para se compreender como algumas famílias acabam agindo em seu lugar, ignorando que eles seriam capazes e outras os deixando de lado ou negligenciando suas necessidades ou até mesmo abandonando-os. Esses dados indicam possíveis conflitos ou maneiras de se pensar o envelhecimento e as necessidades da pessoa na velhice entre as diferentes gerações e, por outro lado, também aponta para a necessidade de se avaliar questões de gênero na ocorrência de violência familiar contra o idoso.

A segunda categoria, Aspectos Potencialmente Geradores de Violência Familiar contra o Idoso, 
discorreu sobre as variáveis individuais e contextuais que interferem no sentido de aumentar a vulnerabilidade à ocorrência da violência contra o idoso. A subcategoria contexto familiar abordou aspectos da estrutura e do funcionamento familiar que, uma vez presentes, colocam os idosos em situação de maior vulnerabilidade. Entre esses aspectos foram citadas a presença de dependentes químicos, questões e história de violência na família.

Os profissionais também consideraram questões em relação a problemas na educação dos filhos na infância, como a falta de limites e não cobrar responsabilidade, repercutindo na relação entre pais idosos e filhos adultos, e ainda o idoso visto como entrave para realização de planos pessoais dos filhos, como aspectos potencialmente geradores de violência contra o idoso, conforme narrativas que seguem.

[...] outro fator é... tem muito da educação da pessoa, o que ela acredita, o que ela pensa da vida, do próprio envelhecer. Acho que muitas das agressões é não suportar alguém que já passou daquela fase, de uma certa idade, já não merece mais estar aqui ou a pessoa está visando a herança e o idoso nunca morre, poderia estar usufruindo disto, 'minha vida está passando e meu pai e minha mãe vivem' assim, é muito louco tudo isso que eu estou falando mas tem essas coisas também. (P6)

O conteúdo dessas narrativas ilustra a objetalização ${ }^{19}$ do outro presente nas relações onde há violência. Nesse sentido, quando não há limites claros nas relações é comum se verificar inversões hierárquicas ou relações hierárquicas fixas e a anulação do outro na busca da autossatisfação, o que pode ser agravado se a velhice for vista apenas como fase de declínio e dependência e o idoso sem uma função para a família, passando a ser alvo de hostilidade pelos conflitos que a sua presença possa gerar.

Os participantes mencionaram a dificuldade dos filhos em retribuir os cuidados recebidos no passado como uma consequência para os idosos do funcionamento familiar em etapas anteriores do ciclo de vida. Os profissionais explicitaram os seus próprios valores de família como um espaço de cuidado mútuo e em suas narrativas foi comum se remeterem aos relacionamentos com os seus próprios pais para ilustrar o que esperam e consideram adequado nas relações familiares com idosos.

Eu tenho meu pai e minha mãe, que brigaram a vida inteira pela gente, fizeram tanto pela gente, agora vou pegar e dizer 'não quero saber, é problema dela, vou cuidar da minha vida',acho que é isso que acontece muito hoje. Não sei, esse ponto aí é difícil definir, depende de cada um. Eu sei que eu jamais vou deixar a minha mãe em qualquer lugar, já disse para ela 'quando estiver cansada vai lá para minha casa, vai ficar comigo' eu penso assim, meus irmãos pensam igualzinho. (P8)

A opinião desses profissionais esteve pautada em suas próprias relações familiares com idosos e reflete as construções sociais quanto ao que norteia as relações familiares, nesse sentido valorizam a sequencialidade de cuidados presente na ideia de que os pais cuidam dos filhos que cuidam dos pais, possível pela existência do afeto que os une. Apontam para a qualidade das relações que garantem a continuidade do suporte emocional e instrumental entre pais e filhos na vida adulta ${ }^{20}$ e que a qualidade dos vínculos prévios entre o idoso e seus familiares pode ser um preditor da qualidade das relações na velhice, bem como do risco de maus-tratos ${ }^{21}$.

A sobrecarga do cuidador foi citada, como no depoimento abaixo, salientando-se as dificuldades enfrentadas por quem cuida de um idoso dependente, seja cuidador formal ou informal.

[...] Agora eu não culpo muitas vezes o cuidador, porque às vezes ela tá trabalhando $24 \mathrm{~h}$ por dia a semana inteira, às vezes eu até defendo, às vezes bate porque está no limite dela, faz uma semana que não vai para casa não vê o marido, os filhos, está o dia inteiro, a paciente gritando, gritando. Quem é que aguenta? (P9)

As pressões externas a que as famílias estão submetidas na atualidade, como do trabalho e financeira, que resultam em pouco tempo para cuidar e dar mais atenção para a necessidade dos idosos também foram apontadas pelos participantes. A narrativa a seguir ilustra a experiência familiar de uma das profissionais que tem a mãe idosa e sente-se dividida entre dar atenção para a mãe, o marido e os filhos e às próprias necessidades, após um dia de trabalho.

O que mais tem são famílias que não têm paciência com seus idosos. Porque eles ficam muito mais carentes e sensíveis e daí eu penso assim, o filho, a filha ou a nora trabalham, chegam com aquela canseira do trabalho, canseira dos filhos deles, da vida deles e ainda tem aquele idosinho precisando sugar eles. Porque você chega num idoso, ele quer te contar tudo, querem te passar as coisas. Eu vejo pela minha mãe que tem 84 anos, eu chego em casa ela quer me contar tudo, fica uma concorrência, ela e meu marido, para me contar o que aconteceu, um conta, outro conta, dai eu vou olhar para um o outro me chama. (P5) 
Devido à presença de fatores externos, os participantes associaram o desinteresse ou o pouco envolvimento dos familiares com o idoso, sustentando o isolamento dentro dos lares. As mudanças na estrutura e funcionamento das famílias, bem como a busca pela autorrealização e as pressões sociais e de trabalho sofridas na atualidade, que acabam levando ao isolamento dos idosos dentro dos lares, indicam a dificuldade de algumas famílias em realizar os ajustamentos necessários frente ao envelhecimento de seus membros ${ }^{22}$.

A subcategoria características do idoso abordou os aspectos individuais com potencialidade de gerar violência contra o idoso. Assim como a história de violência na família foi considerada por alguns participantes, também se referiram ao idoso agressivo com os familiares no presente ou no passado como um fator que pode levar os familiares a também maltratarem o idoso.

Às vezes a gente ouve filhos que dizem 'ah meu pai é insuportável' e com o tempo de atendimento a gente percebe quando foi uma pessoa super complicada, foi uma pessoa que não foi legal para a família e a família tem que suportar. Há muitos anos atrás eu trabalhei no [fala nome de um hospital] e eu lembro que a gente foi levar um idoso para casa e a família disse 'não, aqui ele não vai entrar', o idoso tinha provocado violência, até estupro da filha, agredia a família, a esposa, os filhos, ela dizia 'minha mãe morreu por causa deste homem, eu não quero ele, pode largar onde quiser'. A gente apelava 'mas é seu pai', e ela 'não quero saber se é meu pai, antes eu nunca tivesse conhecido essa pessoa'. (P6)

Esse dado vai ao encontro do exposto na literatura quanto ao fato de os idosos se transformarem em vítimas também em função da violência perpetrada por eles em fases anteriores do ciclo de vida ${ }^{4,21}$. Esse dado também remete ao fato de que a violência, enquanto fenômeno multifacetado deixa o indivíduo exposto tanto ao processo de ser vitimizado como de agressor ao mesmo tempo.

A situação do idoso que nega a dependência (3.2.2) foi mencionada, conforme ilustrado na seguinte narrativa.

[...] Ela é daquelas pessoas com excesso de individualidade, o que também prejudica, a pessoa ser tão independente, tão individual que às vezes prejudica. [...] No idoso é a negação, no caso uma pessoa que não aceita as coisas, daí já entra o quadro mental dele. É porque se ele não aceita ele vai se autonegligenciando, não se cuida, como aquela que eu contei e a justiça é muito lenta. (P4)
A autonegligência, compreendida como os comportamentos da pessoa idosa que ameaçam a sua própria saúde ou segurança pela recusa de prover a si mesma os cuidados necessários ${ }^{4}$, pode ser pensada como a contrapartida do idoso nas relações, ou seja, não basta esperar dos familiares que estejam dispostos a amparar a pessoa idosa se ela mesma não se permitir receber os cuidados aceitando as suas limitações.

$\mathrm{O}$ idoso carente de afeto também foi mencionado e, para exemplificar, citaram mulheres idosas que se tornam vulneráveis quando estabelecem novos relacionamentos afetivos.

O que acontece muito com as idosas é assim, elas se sentem carentes e não raro arrumam um namorado e esses, não é regra geral, mas com alguma frequência vem extrair alguma coisa delas, como dinheiro emprestado. Atendemos várias pessoas que emprestaram dinheiro, iludidas de que o cara iria fazer uma reforma no apartamento para viverem juntos e felizes para o resto da vida, tirou todo o dinheiro da conta e não viu mais o namorado. Algumas não deram o dinheiro, mas levam um soco, uma surra, algumas coisas assim. (P6)

\section{Considerações Finais}

Este artigo buscou apresentar os significados construídos por profissionais que atuam em uma UBS sobre a violência familiar contra o idoso, sendo que seu objetivo foi proposto por se entender que as ações profissionais direcionadas ao manejo de situações de violência familiar podem ser permeadas e/ou influenciadas pelos significados construídos acerca do fenômeno.

Os profissionais expuseram suas expectativas de que a família funcione como amparo e proteção aos seus membros no estágio tardio da vida, sendo considerada violência familiar contra o idoso aquilo que fere esse princípio, como: não cuidar, isolar, asilar, usufruir de seus recursos financeiros e tirar a autonomia daqueles que são capazes de se autogovernar. Nesse sentido, a violência familiar contra o idoso foi pensada pelos profissionais a partir do significado de declínio e fragilidade e o idoso colocado no lugar de vítima, por não receber o amparo adequado por parte da família, ou seja, os profissionais se remeteram principalmente ao idoso frágil e dependente e às questões geracionais associadas ao seu desencadeamento.

Mediante a construção desses significados, evidenciou-se uma visão polarizada que colocou 
o idoso como vítima e a família como responsável por não ser capaz de oferecer um espaço digno de cuidados àquele naturalmente mais frágil. Todos os elementos de análise denotaram, na percepção dos profissionais, a dificuldade ou a incapacidade do familiar ou da pessoa que convive com o idoso, em reconhecer as suas necessidades ou vê-lo enquanto sujeito ${ }^{19}$, ou seja, o não reconhecimento do idoso enquanto sujeito possibilita a dominação, exploração ou opressão e o estabelecimento de hierarquias rígidas, nas quais um fica à mercê da determinação ou vontade do outro. Em suas narrativas, os profissionais ilustraram a questão com os seguintes exemplos: filhos que agridem os pais no presente porque estes já não demonstram a mesma força de outrora quando eram os agressores; filhos que abusam financeiramente ou fisicamente por perceberem que os pais necessitarão receber mais do que têm possibilidade de dar, tornando-se um estorvo em suas vidas; filhos que não assimilaram o valor da retribuição de cuidados e negligenciam as necessidades dos mais velhos; cuidadores esgotados frente à dependência crescente dos idosos; pessoas das relações íntimas que veem no idoso uma oportunidade de ganhos financeiros; e ainda, filhos que tiram ou restringem a autonomia e o livre arbítrio dos pais, impondo-lhes condições a partir de uma relação de funcionalidade mais do que de afetividade, por não considerarem o idoso como um sujeito com potencialidades e desejos, situação que muitos idosos acabam se submetendo por temerem magoar ou perder o afeto de seus familiares.

Pode-se pensar a partir desses dados, que os aspectos que sustentam a "coisificação" do idoso vão se estabelecendo de acordo com a qualidade dos vínculos anteriores e à medida que o idoso não exerce mais relações igualitárias com os membros de sua rede, passando a demandar mais do que ofertar ou a não ocupar o mesmo lugar que lhe conferia poder nas relações. Soma-se a isso, a desvalorização social da velhice, principalmente quando seguida de dependência e os valores presentes na sociedade contemporânea voltados mais para a individualidade e a autorrealização pessoal.

Não se pode deixar de considerar que o idoso incluído nesse contexto também valoriza sua independência e individualidade e, face às limitações do envelhecimento, relute em abrir mão de suas conquistas e autonomia para estabelecer uma relação de maior dependência com filhos ou cuidadores, o que pode culminar em uma violência autoinfringida, como foi apontado nos relatos dos participantes. Outra questão que também precisa ser levada em conta são as dificuldades decorrentes da tendência atual ao não esvaziamento do ninho, que leva à convivência entre diferentes gerações com necessidades que podem ser conflitantes, presente em um número cada vez maior de famílias.

Os diversos fatores relacionais precisam ser compreendidos e contemplados a fim de que os profissionais possam auxiliar as famílias a enfrentar conflitos que, se somados a outros fatores externos que exercem pressão sobre o seu funcionamento, podem aumentar as possibilidades de não conseguirem realizar as suas atribuições, entre elas, oferecer espaço para o envelhecimento de seus membros. Compreender a complexidade dos fatores que podem se sobrepor e aumentar a vulnerabilidade dos idosos à violência familiar é fundamental para a abordagem dos casos e para que o profissional não se prenda a uma leitura linear da situação visualizando apenas vítima e agressor, visão que tende mais a culpabilizar a família pelas suas insuficiências ou falhas e menos a auxiliá-la na busca de possíveis soluções para os seus problemas.

Outro ponto que merece ser considerado é que os significados sobre a violência familiar contra o idoso estiveram focados no aumento da dependência devido ao processo de declínio físico e/ou cognitivo. Apesar de essa condição aumentar a vulnerabilidade, não são apenas os idosos dependentes que vivenciam situações abusivas. O significado pode favorecer a que o profissional não associe a possibilidade de um idoso com independência e autonomia também estar envolvido em situações de violência familiar.

Nessa direção, cabe chamar atenção para as agressões existentes na relação conjugal, seja as que iniciam ou se estendem até a velhice, como também dos abusos dos filhos em relação às mulheres idosas, pautadas em questões de gênero. Estas, presentes na violência familiar contra idosos apareceram de forma subjacente nas narrativas dos profissionais participantes, mas pelo fato de estarem voltados aos significados de fragilidade do idoso, não se detiveram a analisar a questão. Portanto, o rastreamento de casos de violência familiar contra idosos não deve estar focado somente na condição de fragilidade física e/ou cognitiva, mas na qualidade da relação familiar.

Considera-se que subjugar o olhar sobre a violência a determinados aspectos da mesma é empobrecer as práticas profissionais. Nesse sentido, os dados apresentados contribuem para a compreensão e a ampliação da temática aborda- 
da, gerando subsídios para melhor sustentar a clínica ampliada em saúde, proposta pela Política Nacional de Humanização $0^{23}$, principalmente no que se refere à temática da violência.

No processo de trabalho, os profissionais de saúde estão expostos cotidianamente aos diferentes tipos de violência. Diante desse fato, torna-se necessário um processo de sensibilização constante, através da educação continuada ou permanente e que se caracterize por oferecer espaço para o diálogo, que possibilite uma necessária reflexão pessoal e profissional, uma vez que uma não pode prescindir da outra. Entende-se que no processo de sensibilização, além da infor- mação científica especializada é fundamental que se inclua espaços de reflexão sobre as dificuldades que vão além da práxis específica de cada área de atuação, pois o trabalho com violência exige o pensar para além das fronteiras disciplinares, para que assim se possa gerar melhores estratégias de escuta e de intervenção.

Visando ampliar continuamente o campo de conhecimento acerca da violência familiar e as possibilidades de agir profissionalmente no sentido de combatê-la, propõe-se que futuros estudos abordem se a ambiguidade na definição dos atos de violência geram ambivalência no profissional, impedindo-o de dar visibilidade à mesma.

\section{Colaboradores}

ACNS Wanderbroocke participou da concepção da pesquisa, coleta e análise de dados e concepção e redação do artigo; CLOO Moré participou da concepção da pesquisa, análise dos dados, revisões críticas e final do artigo. 


\section{Referências}

1. Minayo MCS. Violência e saúde. Rio de Janeiro: Editora Fiocruz; 2006.

2. Brasil. Lei no 8.842 , de 4 de janeiro de 1994. Dispõe sobre a Política Nacional do Idoso, cria o Conselho Nacional do Idoso e dá outras providências. Diário Oficial da União 1994; 5 jan.

3. Brasil. Estatuto do Idoso. Lei $n^{\circ} 10.741$, de $1^{\circ}$ de outubro de 2003. Diário Oficial da União 2003; 3 out.

4. Brasil. Secretaria Especial dos Direitos Humanos. Plano de Ação para o Enfrentamento da Violência contra a Pessoa Idosa. Brasília: Secretaria Especial dos Direitos Humanos; 2007.

5. Valadares FC, Souza ER. Violência contra a pessoa idosa: Análise de aspectos da atenção de saúde mental em cinco capitais brasileiras. Cien Saude Colet 2011; 15(6):2763-2774.

6. Collins KA. Elder maltreatment: a review. Arch Pathol Lab Med 2006; 130(9):1290- 1296.

7. Minayo MCS. Violência contra a pessoa idosa: o direito pelo avesso. In: Papaléu Netto M, organizadores. Tratado de gerontologia. São Paulo: Atheneu; 2007.

8. Killick C, Taylor BJ. Professional decision making on elder abuse: systematic narrative review. Journal of Elder Abuse and Neglect 2009; 21(3):211-238.

9. Hanada H, D'Oliveira AFPL, Schraiber LB. Os psicólogos na rede de assistência a mulheres em situação de violência. Estudos Feministas 2010; 18(1):288. [site da internet] [acessado em 2010 jul 30]. Disponível em: www.periodicos.ufsc.br/index.php/ref/ article/view/13504

10. Bonfim EG, Lopes MJM, Peretto M. Os registros profissionais do atendimento pré-natal e a (in)visibilidade da violência doméstica contra a mulher. Esc. Anna Nery Rev Enferm 2010; 14(1):97-104.

11. Fuster EG. Las víctimas invisibles de la violencia familiar. El extraño iceberg de la violencia doméstica. Buenos Aires: Paidós; 2002.

12. Riffiotis T. Nos campos da violência: diferença e positividade. LEVIS: Laboratório de Estudos da Violência. Universidade Federal de Santa Catarina; 2006. [site da internet] [acessado em 2008 ago 15]. Disponível em: http://www.cfh.ufsc.br/ levis/publicacoes/ artigos.shtml

13. Gergen KJ. Realidades y relaciones: Aproximaciones a la construción social. Barcelona: Paidós; 1996.

14. Sluzki CE. A rede social na prática sistêmica: alternativas terapêuticas. São Paulo: Casa do Psicólogo; 1997.
15. Strauss A, Corbin J. Pesquisa qualitativa. Técnicas e procedimentos para o desenvolvimento de teoria fundamentada. Porto Alegre: Artmed; 2008.

16. Chaves PGS, Costa PL. A violência afetiva e a violência doméstica contra os idosos. Belo Horizonte, 2003. [site da internet] [acessado em 2009 ago 15]. Disponível em: http://www.mj.gov.br/Senasp/senasp/artigo/ violen_idoso.html>

17. Comerlato EMB, Guimarães I, Alves ED. Tempo de plantar e tempo de colher: as representações sociais de profissionais de saúde e idosos sobre o processo de envelhecimento. Rev. Eletrônica de Enfermagem 2007; 9(3):736-747.

18. Fonseca RP, Trentini CM, Valli F, Silva RAN. Representações do envelhecimento em agentes comunitários da saúde e profissionais da enfermagem comunitária: aspectos psicológicos do processo saúdedoença. Cien Saude Colet 2008; 13(4):1275-1284.

19. Ravazzola MC. Histórias infames: los malostratos en las relaciones. Buenos Aires: Paidós; 2005.

20. Penso MA, Morais IA. O ciclo da violência em famílias com idosos. In: Faleiros VP, Loureiro AML, Penso MA, organizadores. O conluio do silêncio. A violência intrafamiliar contra a pessoa idosa. São Paulo: Roca; 2009.

21. World Health Organization (WHO). World report on violence and health. Genebra: WHO; 2002.

22. Carter B, McGoldrick M. As mudanças no ciclo de vida familiar. Uma estrutura para a terapia familiar. In: Carter B, McGoldrick M, organizadores. As mudanças no ciclo de vida familiar. Uma estrutura para a terapia familiar. Porto Alegre: Artes Médicas; 1995.

23. Brasil. Ministério da Saúde (MS). HumanizaSUS: Politica Nacional de Humanização: A humanização como eixo organizador de todas as práticas de atenção e gestão em todas as instâncias do SUS. Brasília: MS; 2004. [site da Internet] [acessado 2010 jan 20]. Disponível em: portal.saude.gov.br/portal/arquivos/ pdf/doc_base.pdf

Artigo apresentado em 01/07/2011

Aprovado em 09/09/2011

Versão final apresentada em 15/09/2011 